\title{
POST-OCCUPANCY EVALUATION: A REVIEW OF LITERATURE
}

\author{
C.J. Roberts
}

Faculty of Computing, Engineering and the Built Environment, Birmingham City University, Birmingham, UK

David John Edwards

Faculty of Computing, Engineering and the Built Environment, Birmingham City University, Birmingham, UK and University of Johannesburg, Johannesburg, South Africa

M. Reza Hosseini

School of Architecture and Built Environment, Deakin University, Geelong, Australia and Centre for Research in Assessment and Digital Learning, Deakin University, Melbourne, Australia

Monica Mateo-Garcia

School of Engineering and the Built Environment, Birmingham City University, Birmingham, $U K$, and

De-Graft Owusu-Manu

Department of Building Technology, Kwame Nkrumah University of Science and Technology, Kumasi, Ghana

\section{ABSTRACT}

Purpose: This paper seeks to: analyse extant literature on POE of a building's operations and performance as a means of holistically mapping the existing body of knowledge (BoK); identify impediments preventing its wide scale adoption throughout practice; and develop new theory that seeks to integrate digital technologies (such as building information modelling (BIM)) within facilities management (FM) via a POE feedback mechanism.

Approach: An inductive and interpretivist methodological approach is adopted that utilises a mixed methods systematic review to map bibliometric data on the POE, associated underpinning processes and benchmarking facilities. Publication and citation metrics are produced via the software VOSviewer to determine the extent to which POE interrelates with other fields of study (namely, digital technologies and facilities management (FM)).

Findings: The body of knowledge (BOK) accrued illustrates that whilst POE has received comparatively scant academic attention in comparison to other fields of study, interest in the area is growing. The work also identifies that a stronger community of practice (CoP) is needed (that comprises of academics and practitioners) to ensure that a consistent approach to POE implementation is developed and that the barriers to POE implementation are addressed. 
1 Originality/ value: Findings presented accentuate the need for design practitioners to reverse engineer POE implementation to inform future design vis-a-vis simply reporting upon an existing building's performance post construction. Other new theories are also introduced as a means of engendering wider academic discourse in this field of science.

\section{KEYWORDS}

Post-Occupancy Evaluation, VOSviewer, Interpretivist Methodological Approach, Bibliographic Data, Body of Knowledge.

\section{INTRODUCTION}

The Architecture, Engineering, Construction and Operations (AECO) sector is responsible for creating and managing the built environment (both buildings and infrastructure) to facilitate human activities (i.e., work, leisure and housing) over time. Creating this man-made environment directly impacts upon the people who inhabit or use buildings and infrastructure but also the surrounding environment. For example, buildings: are major consumers of environmentally polluting natural resources (Milutienè et al., 2012); are essential to socio-economic development (Acharya and Sadath, 2019); and can impact upon occupants' health and well-being (Al horr et al., 2016). Within the whole life cycle of a built asset's life, conspicuous academic attention is paid to the design and construction phases (Kessem et al., 2014; Roberts et al., 2018). However, it is the operational phase of building occupancy and use that is the chief contributor to pollution, whole life cycle costs and performance metrics (c.f. Bosch et al., 2014; Liu and Issa, 2014; Lindkvist, 2015; Nical and Wodynski, 2016). For this reason, far greater attention is needed to review and evaluate building performance in-use.

To measure a building's operations and performance, a post-occupancy evaluation (POE) is typically utilised to determine whether decisions made by the design, construction and facilities management professionals have met the envisaged requirements of end-users and the development's commissioners (Adeyeye et al., 2013; Skills Funding Agency, 2014). Such work has significant implications in the area of soft landings (within a building delivery process) by ensuring that future decisions made about similar buildings designs are based upon lessons learnt from an existing building's operational performance and the fulfilment of client and user requirements (Gana et al., 2018). POE considers a broad range of diverse performance metrics including: building use, energy consumption, maintenance costs and user satisfaction (c.f. RIBA, 2016; RIBA, 2017a; RIBA, 2017b). A building’s operational performance is measured using: i) 
project team feedback that recounts the commissioning and construction phases; ii) end-user feedback on finishes and functional performance; iii) technical performance feedback from a building's systems; and iv) a strategic overview incorporating the data from each of the aforementioned evaluation stages (c.f. HEFCE, 2006; RIBA, 2016; RIBA, 2017a; RIBA, 2017b).

The widely espoused beneficial implications of POE implementation include: i) transference of operations knowledge accrued in order to inform future building designs (Cooper, 2001); ii) iterative improvement of an existing facility's performance (Göçer et al. 2015); and iii) the ability to benchmark building performance between facilities, particularly within the same estate (Preiser and Vischer, 2005; Olivia and Christopher, 2014). However, practitioners have hitherto either failed to adopt a POE or lacked consistency in approach to its implementation (Alborz and Berardi, 2015). Part of the lack of consistency issue can be attributed to the various POE implementation strategies found within literature and practice (cf. Riley et al., 2010). Consequently, the opportunity to reduce excessive energy usage, reliance on resources and material wastage is squandered, whilst financial returns on investment and occupant satisfaction are simultaneously reduced (Ahuja et al., 2016). Research suggests that the accrual of value and passive attitudes toward sustainable solutions represent major stumbling blocks that discourage sector stakeholders (i.e. designers, contractors and clients) from completing a POE (Wong and Kuan, 2014). Increased societal and political demands for 'greener buildings' may aid in dispelling these unduly negative attitudes (Miller et al., 2012).

Against this contextual backdrop, this research seeks to: analyse extant literature on POE of a building's operations and performance as a means of mapping the existing body of knowledge (BoK); identify impediments preventing its wide scale adoption throughout practice; and develop new theory that would seek to integrate digital technologies within facilities management (FM) via a POE feedback mechanism. Both industry guidance and academic literature are reviewed to: construct an overview of the differing POE strategies available to building commissioners and developers; and identify the interconnectedness of key authors undertaking contemporary POE research. Cumulatively, this accrued BOK is then utilised to determine the extent to which POE interrelates with other fields of study. These other fields include: digital technologies such as senor based networks and building information modelling (BIM) which are increasingly being used to tailor a building's performance to individual occupant needs; and facilities management (FM) where FM teams are the custodians of buildings and utilise POE findings to modify buildings inuse (cf. Parn et al., 2017). Concomitant research objectives are to: provide insightful guidance on 
1 POE implementation throughout a building's whole life cycle; generate new theories on POE usage within practice; and propose future avenues of investigative research that will augment current and future building design, construction and performance.

\section{RESEARCH APPROACH}

From an overarching epistemological perspective, an inductive and interpretivist methodological approach was adopted utilising a mixed methods systematic review of pertinent literature to generate new theories on POE. This research approach was adopted because an interpretation of academic and professional practice literature enabled the development of new theories using inductive reasoning; where the latter represents the first step towards developing a much clearer ontological perspective of the POE phenomena under investigation (Suddaby et al., 2015). Petticrew and Roberts (2008) and Oraee et al. (2017) assert that a 'mixed methods systematic review' is the most effective method for identifying gaps in a BOK. In contrast to a 'mono-method manual systematic review', it is resistant to biases realised through subjective interpretation and judgement (He et al., 2017). Within this overarching methodological framework, a two stage operational process was adopted. In stage one, a detailed review of building performance measurement using POE was undertaken to contextualise the research and further delineate the specific areas of POE evaluation, process and benchmarking.

In stage two, bibliometric data was mapped to provide a systematic review of relevant extant literature. Hayvaert et al. (2016) state that the amalgamation of quantitative and qualitative methods requires the development of a protocol stating methods, processes and sampling strategies for both data collection and study objectives. With this in mind, an iterative search protocol was developed which utilised three bibliometric data searches incorporating the following pertinent terminologies: i) ‘POE'; ii) 'POE' and 'process'; and iii) 'POE', 'process' and 'benchmark'. Data utilised to produce the bibliometric map could be sourced from a number of electronic repositories, for example: Web of Science, ProQuest and Scopus. However, Web of Science was utilised because it claims to be the most accurate citation database available for bibliometric analysis (Clarivate Analytics, 2017). Each search sought to capture literature that contained the selected terms in the abstract, title or keywords of published work. To avoid conflation with unrelated studies pertaining to alternative disciplines, the term 'Poe' was excluded to ensure the results related to the built environment and not to other disciplines. 
1 The Web of Science repository allows for the tailoring of searches to meet specific needs, such as the date of citation. No limit on the date of citation was implemented (1970-2018) to secure a more complete perspective on the entire POE BOK. The first two searches were conducted using the VOSviewer bibliometric analysis software in order to construct bibliographic visualisations and map the interconnections between authors researching the three topic areas. The bibliometric data sourced from the Web of Science was organised using the repository's 'analyse' function to indicate the top 25 academic journals publishing POE research. A third stage of analysis was conducted manually and was not restricted to the top 25 academic journals as the search generated only seven results. The Web of Science search functions were also utilised to discern key statistics (date of first citation and total number of research items) with which to critically compare similarly aligned disciplines pertaining to the design, construction and operational phases of a development's life cycle (i.e. BIM and FM).

\section{BUILDING PERFORMANCE AND MEASUREMENT}

Each year, buildings produced and operated by the AECO sector consume 40 per cent of global anthropogenic material and energy flows, 25 per cent of total timber harvested and 16 per cent of freshwater (Milutienè et al., 2012). These unsustainable rates of consumption mean that the sector consequently engenders monumental environmental impact, for example, per annum the sector contributes: 24 per cent of India's $\mathrm{CO}_{2}$ emissions; 33 per cent of Canada's energy production; and 42 per cent of Australia’s normalised solid waste (El shenawy and Zmeureanu, 2013). Globally, buildings' life cycles account for 40 per cent of energy requirements and carbon dioxide emissions and 70 per cent of total greenhouse gas emissions (Motawa and Carter, 2013; Lui et al., 2015). Against this statistical backdrop, Cooper (2001) and Riley et al. (2010) assert that buildings constructed using contemporary design and construction innovations, without process feedback on performance, effectively remain an unproven prototype. Yet the majority of a building's environmental impact occurs during the operational phase, which may last several decades (Guo and Wei, 2016). To further exacerbate matters, occupants spend more time indoors - within the United States for example, people spend up to 90 per cent of their time within buildings that constitute a 120 million real estate stock and account for 40 per cent of the nation's total annual energy requirements (Shoubi et al., 2014). Consequently, the AECO sector's unsustainable record of poor environmental performance during a building's construction and operation phases renders a laissez-faire 'business as usual' attitude untenable (Ahuja et al., 2016). During these phases buildings require expert management of budgets, schedules and environmental impact to enhance returns on investment, mitigate wastage/environmental impact and augment occupancy 
satisfaction (Ahuja et al., 2016). Herein resides the inherent importance of a POE and its innate ability to provide invaluable reflection upon a building’s performance.

\section{Post-occupancy Evaluation (POE) Implementation}

POE encompasses an expansive range of processes and activities that systematically evaluate a building's performance subsequent to its handover (Ilesanmi, 2010; Tookaloo and Smith, 2015). Traditionally, building performance knowledge was passed down through generations of construction specialists who possessed exhaustive tacit knowledge of a client's cultural, social, operational, technical and economic parameters (McGrath and Horton, 2011). The Royal Institute of British Architect (RIBA) report "Plan of Work for Design Team” (1965) first introduced the concept of an architect returning to a completed development to assess its success and/or identify areas for improvement (RIBA, 1965). However, despite fifty years of subsequent development, the vast majority of discourse on POE planning and implementation is generated via real estate departments of higher education institutions and is not routinely applied throughout the wider AECO sector (Leaman, 2004; Hadjri and Crozier, 2008; Zhang and Barrett, 2010).

When implemented for a newly developed facility, POE can accrue various benefits in terms of: maximising space utilisation, reducing operational costs and optimising maintenance costs (c.f. Shohet et al., 2003; RIBA, 2016; RIBA, 2017a; RIBA, 2017b). However, the roles, responsibilities, perspectives and expectations of both industry practitioners and built asset endusers differ significantly (Rebaño-Edwards, 2007). For instance, whilst developers are primarily concerned with efficiency and cost (Gervásio et al., 2013), end-users focus more upon the quality of the building's finishes, its environmental performance and services (Turpin-Brooks and Viccars, 2006; Hassanain and Mudhei, 2006; Riley et al., 2010; Choi et al., 2012; Hussanain and Iftikar, 2015). Regardless of perspective, prudent business decision making for buildings requires the efficient management of data and information (García-Peñalvo and Conde, 2013; Gong et al., 2018). Undertaking a POE presents a significant opportunity to garner insightful feedback on the design, construction and management decisions taken during the building's whole life cycle (O’Neil and Duvall, 2005; Skills Funding Agency, 2014). POE reports can contain invaluable data regarding: i) end-user feedback of facility performance; ii) project team feedback regarding the design and construction phases; iii) technical data from the facility's building management system; and iv) strategic data from an organisation's estates management perspective (HEFCE, 2006; RIBA, 2016; RIBA, 2017a; RIBA, 2017b). Garbowski and Mathiassen (2013) assert that sound real estate decision-making is crucial to ensuring an organisation's financial and strategic success. Additionally, García-Peñalvo and Conde (2013) proffer that the more useful the available 
1 information, the more efficient and considered the decision-making process will be. However, 2 despite voluminous 'big data' available, significant gaps are apparent between a building's 3 predicted and actual performance (de Wilde, 2014; Brown, 2015).

\section{Barriers to POE Implementation}

6 Curiously, the implementation of POE is inconsistent internationally and prevailing practice within 7 the United States is far more advanced than international counterparts (Adewunmi et al., 2010).

8 Within the UK, two prominent guidance documents offer insight into the financial importance of 9 a POE. The Higher Education Funding Council England (HEFCE) Guidance to Post-occupancy

[Insert Table 1 about here]

i) ownership - a prevailing culture of litigation and blame present major stumbling blocks to POE implementation - an issue further exacerbated by blurred lines of responsibility for such (Riley et al., 2010; Jiao et al., 2013);

ii) cost, procurement and incentives - the cost of, and value perceived from conducting a POE create significant barriers to POE adoption (c.f. Zimmerman and Martin, 2001; Vischer, 2001). Contractual clauses within a chosen procurement path could alleviate this issue but at the conception stage, anecdotal evidence (sourced from the authors' own industrial experiences as a practitioner and informal conversations held practitioner colleagues) suggests that a POE is hardly considered. Financial and non-financial incentives could also be employed but at present these are not well defined or utilised; and 
iii) education and culture - architects and designers are at the forefront of the client interface during project inception and yet, POE and its implementation rarely feature in architectural courses awarded (Cooper, 2001). When a POE is used the process adopted is often subject to variability and personal choice (of the person(s) implementing the POE) thus making direct comparisons between buildings difficult. This knowledge void further compounds the problem of POE adoption.

\section{The POE Process}

The POE process is steered by research pertaining to human requirements, built asset performance and FM (Riley et al., 2010). It consists of two prominent lines of investigation, namely: i) technical performance; and ii) functional performance (Hassanian et al., 2017). Technical performance measurement represents an assessment of the background environment provided by a building for conducting its intended activities (Preiser et al., 1988). Technical performance considerations evaluate: thermal comfort; acoustical performance; visual comfort; indoor air quality; and fire safety (McGrath and Horton, 2011; Hassanian et al., 2017). In contrast, functional performance measurement evaluates whether a building is fit for purpose when considering user activities. Functional performance considerations evaluate: space management; interior and exterior finishes; proximity to other facilities; and human factors (Zhang and Barrett, 2010). Although various strategies for conducting a POE exist, it is these two lines of investigation (functional and technical performance measurement) that predominate (refer to Table 2).

\section{[Insert Table 2 about here]}

From a higher education perspective, POE implementation seeks to determine whether the institution’s FM operations meet University objectives (Tookaloo and Smith, 2015). Conducting a POE in this context standardises best practice, increases the accountability of facility managers and ensures that higher education institutions realise the improvements identified by the POE in future developments (Mustafa, 2017). The primary guidance document informing POE in English Higher Education is HEFCE's Guidance to Post-occupancy Evaluation which offers a toolkit for planning and implementation (HEFCE, 2006). HEFCE guidance is ostensibly designed to allow flexibility, stating that it is: "prepared so colleagues can choose according to their needs and preferences, as few or as many of the areas identified in the report” (HEFCE, 2006, p.3).

\section{POE Benchmarking}


POE findings provide benchmark criteria for comparing one facility's quality of finish, services and performance against another’s (Wauters, 2005; Hassanain et al., 2016) and offer guidance to improve future developments (Tookaloo and Smith, 2015). However, benchmarking facility performance via POE is problematic due to industry reservations that any value accrued is largely beneficial to industry competitors vis-à-vis the developer commissioning the evaluation (Olivia and Christopher, 2014). Zeisel (1981) states that the built environment design process should be cyclical, rather than being initiated and concluded in accord with the specific building's design and construction phases. This is further reinforced by Zimmerman and Martin (2001) who propose that POE forms a 'logical final step' to the cyclical process, providing a basis of 'lessons learned' which are fed forward into future developments. Similarly, Leaman and Bordass (2001) introduce the concept of 'virtuous circles of improvement' where POE is implemented as a benchmarking strategy throughout the design phase. This approach fosters a dynamic, continually evolving BOK to engender continuous improvement throughout the design and construction phases as opposed to final feedback at the handover (c.f. Leaman and Bordass, 2001, p.151). However, despite a variety of POE benchmarking strategies, Green and Moss (1998) suggest that organisations must implement knowledge cycles based upon their facility's bespoke management requirements (Hadjri and Crozier, 2008).

\section{BIBLIOMETRIC ANALYSIS}

Bibliometric analysis has been developed and utilised across multiple disciplines due to its ability to visually represent a large body of literature (van Eck and Waltman, 2010). In contrast to manual analysis, bibliometric analytical software such as Gephi (Bastian et al., 2009) or VOSviewer (van Eck and Waltman, 2010) avoids introducing researcher bias and removes time and resource limitations relating to the practical number of studies selected (He et al., 2017). Visual representation of bibliometric data also allows an academic topic to be expediently and comprehensively investigated (Cobo et al., 2011). VOSviewer constructs distance-orientated network maps where each node/cluster represents the occurrence of a term or author, dependent upon the map generated. Nodes/clusters can also be assigned different colours within a visualisation, differentiating them from other nodes/clusters. VOSviewer's clustering function represents an advancement on previous mapping techniques, allowing deeper observations of connectedness than were previously possible using alternative software such as Statistical Package for the Social Sciences (SPSS) and Pajek (c.f. van Eck and Waltman, 2010). The distance between nodes/clusters gives a better indication of the strength of relationship between these items when 
compared to graph-based maps (Waltman et al., 2010). The analysis of direct citations can also pinpoint the most influential studies within a specific field under investigation.

To produce citation visualisations for POE, the minimum number of papers published by an academic was arbitrarily set at two and the minimum number of citations was also set at two. These minimum values were selected to reflect the POE BOK which in comparison to alternative areas of built environment research, returns a relatively small sample size of applicable published research. For example, a Web of Science search on the term 'Building Information Modelling' returns 51,937 results (May, 2018) compared with 516 results for the term 'Post-occupancy Evaluation' (May, 2018) - hence, POE represents a mere $0.98 \%$ of the available BIM BOK. Three varieties of visualisation were produced: i) co-authorship visualisation; ii) term density visualisation; and iii) a term date visualisation for the whole POE BOK. To maintain a systematic approach, the same specifications and settings were applied throughout the analysis to ensure consistency and for each visualisation fractional counting was utilised. van Eck and Waltman (2014) recommend using fractional counting when producing visualisations. Both full counting and fractional counting utilise the number of documents co-authored by two authors when formulating connections, however fractional counting also takes into account the total number of authors of each of the co-authored documents (ibid).

When producing the term density visualisations, a number of specifications and filtering methods were applied. First, the minimum number of occurrences of a term for it to be considered significant was set at 12 following trial and error experimentation - too low a number and less significant terms could complicate the final visualisation but too high a number and significant terms would be omitted. Second, VOSviewer provides options to manually remove irrelevant terminology not pertaining to the visualisation; in this instance common research terms such as 'introduction' and 'conclusion' were removed because whilst important to research per se, they do not contribute to the theoretical lens of POE. The term date visualisation generated for this study utilised the same data and specifications used to analyse term density, but the 'date overlay' function within VOSviewer was applied as opposed to the 'density overlay'. This was done to ascertain the chronological development of various components of a POE emanating from academic literature pertaining to the POE BOK. The final stage of analysis examined the interconnectedness of publications discussing 'Post-occupancy Evaluation', 'Process' and 'Benchmarking'. This focused search returned only seven research papers. Each paper was manually examined to ascertain: i) date of publication; ii) publishing journal; iii) total number of 
citations per research item; iv) average number of citations; and v) the total number citations combined. These metrics offered insight into the interconnections between research into this specific topic within the larger POE BOK and the chronological development of POE, process and benchmarking research.

\section{FINDINGS}

The research findings for the bibliometric analysis are reported upon within the three iterative and thematic groups analysed in the visualisations, namely: POE literature; POE literature with a focus upon process; and qualitative analysis of literature pertaining to POE, POE process and facility benchmarking.

\section{POE Literature}

Figure 1 depicts a citation visualisation for the POE BOK indicating the strength of connections between authors who have published POE research. Of the 1122 individual authors who have cumulatively published 516 papers, only 119 authors remained once the filtering specifications were applied (i.e. two papers and two citations). Although VOSviewer's program functionality permits selection of authors who are linked through co-authorship (thus removing the nodes which share no direct link), for this visualisation unconnected nodes were included to expose the 39 authors working in isolation, with no co-authorship links with any other researchers within the POE BOK. The unconnected authors displayed can be observed as being equidistant from the central linked cluster, or as having a weak relationship with the centrally located connected academic material. Figure 1 reveals eight distinct clusters where co-authorship between authors is indicated by representation of the same colour. The notably small distances separating independent clusters indicates strong connectedness in terms of citations between each cluster and its corresponding author(s). This indicates that the community of researchers working on POE represented in the central cluster are closely linked. Prominent authors noted include: Bordass and Leaman (2005) who reviewed a portfolio of POE feedback techniques; Baird (2010) who examined the relationship between POE and post occupancy review of buildings and their engineering (PROBE); and Husin et al. (2012) who attempted to link POE to safety for low cost housing in Malaysia. 
2 Figure 2 presents a density visualisation of key terms and phrases emanating from the POE BOK.

3 The overlay colour(s) presented on the visualisation are predicated by the number of items which 4 appear within the neighbourhood - where the latter refers to the items populating a point/area 5 within a visualisation which share common properties. The higher the density of items within the 6 neighbourhood, the warmer the colour produced, where blue represents no connection and red 7 represents the strongest connection (van Eck and Waltman, 2014). Two distinct density clusters can immediately be observed, with a further seven sub-clusters present within each. The first density cluster, located to the left hand side of the visualisation, has the term 'process' at its centre. Moving out from this centre point are the terms: framework; design process; interview; occupancy; nature; effectiveness; architecture; staff; facility; student; school; and university. The visualisation suggests that all of these terms share a strong relationship which centres upon the fulcrum of the process of conducting a POE - hence, this cluster can be conveniently assigned the nomenclature 'POE process implementation'. This cluster supports the earlier work of Göçer et al. (2015) who sought to develop a collaborative effort of continuous building performance improvement by using the results of POE implementation embedded into BIM. The second density cluster has no defined centre but rather consists of four sub-clusters: system; occupant; comfort; and satisfaction. The fulcrum of these sub-clusters orientates around occupant/ building user feedback and consequently the cluster is assigned the nomenclature 'POE building user feedback'. This cluster supports Preiser's (1995) ground breaking work that sought highlight the importance of POE to facility managers in terms providing a tool with which to systematically identify and evaluate critical aspects of building performance.

[Insert Figure 2 about here]

Figure 3 represents the previous density visualisation with the citation date overlay applied to illustrate when specific topics under the larger POE umbrella received specific academic attention (c.f. van Eck and Waltman, 2010). The figure illustrates that 'occupancy' (particularly regarding hospitals, schools, universities and residential property) was at the forefront of academic attention from 2010 to 2012, whilst between 2011 and 2012 the focus was upon: 'processes', ‘measurement', ‘feedback’ and 'climate’. Between 2012 and 2013, ‘systems', 'energy', and 'satisfaction' (comfort, lighting and temperature) received prominent academic attention. During 2014 'indoor environmental quality', 'health' and 'occupant behaviour' received the most academic attention whilst 'simulation' appears from 2014 onwards. The body of research on POE 
for passive buildings revealed problems with indoor air quality and comfort due to 'building tightness'; where the latter refers to virtually hermetically sealed buildings and environmental efficient building - this research could explain the higher number of citations concerning health and indoor air quality as reported in Figure 3.

\section{[Insert Figure 3 about here]}

A breakdown of the POE BOK organised by journal publication was also analysed. The journals most frequently publishing POE were: Building Research and Information (frequency $(f)=42$ ); Building and Environment ( $f=35$ ); and Energy and Buildings ( $f=23$ ). Within the remaining journals publishing POE, publication frequency fell from Journal of Architecture and Planning Research ( $f=19$ ) down to multiple journals publishing four items or less.

\section{Process Focus within POE Literature}

Figure 4 depicts a co-authorship visualisation of 'POE' and 'process' literature. Of the 292 authors who published 111 research items, only 12 remain after applying filtering specifications. Nodes which share no connections with any other items within the visualisation are again included to offer an insight into the overall connectedness of literature. Of the 12 authors who met the threshold, only five are connected through co-authorship. The observable significant spacing between each node and differing cluster colour indicates that said authors listed in this visualisation are not linked by co-authorship and work in relative isolation. Of the 292 authors who have published research on the topic of 'POE' and 'process', only five (1.71\%) were linked through co-authorship. This lack of interconnections could possibly explain why standardised POE implementation strategies in practice remain elusive. Interestingly, the total number of citations pertaining to POE and process have grown exponentially since 2010 - indeed, as of May 2018, the number of citations has already surpassed the total annual citations recorded in 2013. Hence, although interest in the area remains relatively small, research undertaken is rapidly increasing in volume.

\section{[Insert Figure 4 about here]}

A term density map of 'POE' and 'process' bibliometric data is presented in figure 5. There is a notably significantly smaller set of terms arising from this visualisation with four distinct clusters being identified, namely: analysis; user; performance; and quality. These clusters offer an insight 
into the research currently being undertaken regarding POE and processes and represent the four key areas of research within this niche. The Web of Science bibliometric data regarding 'POE' and 'process' was also organised to indicate the top 25 academic journals under which the research has been published. Journals with the highest frequency of publication were: Building Research and Information ( $f=16)$; and Herd Health Environments Research Design Journal $(f=10)$. Within the remaining journals, publication frequency fell from that of Energy and Buildings $(f=4)$ to multiple conferences with one publication each.

[Insert Figure 5 about here]

\section{Analysis of Literature Pertaining to POE, POE Process and Facility Benchmarking}

A synthesis of literature pertaining to the search terms 'POE', 'process' and 'benchmark' identified only seven research items, of which six have been cited since publication (c.f. Zagreus et al., 2002 [88 citations]; Zimmerman and Martin, 2001 [77 citations]; Bordass and Leaman, 2005 [33 citations]; Curwell et al., 1999 [14 citations]; Elijah-Barnwell and Friedow, 2014 [2 citations]; Gorgolewski et al., 2016 [1 citation]; and Kujawski, 2013 [0 citations). Of these six items, four papers published between 1999 and 2005 dominate the citation ranking, making up 98.60\% of the total citations emanating from this group. The two later items (published 2014 and 2016) contributed three citations between them.

Figure 6 shows a density visualisation map of key term occurrences using the search results for 'POE', 'process' and 'benchmark' terms. As before, the number of occurrences required for a term to be considered significant was set at 12. Five distinct clusters can be observed: i) construction and comparison; ii) benchmarking, maintenance and feedback; iii) client, survey and case study; iv) engineering, occupant satisfaction and occupant; and v) owner and benefit. Of these five clusters, three exhibit a stronger concentration, namely cluster i, cluster iii and cluster v. A sixth cluster regarding 'best practice' can be observed within the visualisation located equidistant from the other five clusters, which suggests that the concept of best practice is crucial as it arises in all of the other clusters. Bibliographic search results for this stage of the analysis were broken down to examine pertinent journals publishing on this topic. These journals were: i) Building Research and Information ( $f=3)$; ii) Herd Health and Environment Research Design Journal $(f=1)$; iii) Indoor Air $(f=1)$; iv) Journal of Green Building $(f=1)$; and v) Sustainable Building and Refurbishment for Next Generations $(f=1)$. 
DISCUSSION

The analysis presented highlights that a small number of POE researchers are working in relative isolation; this finding generates new theory that suggests that a prevailing lack of a cohesive 'community of practice' (CoP) in this important area should be resolved by the creation of a cross industry-academic body to promote, regulate and govern POE implementation. Interestingly, 'POE process implementation' and 'POE building user feedback' were identified as significant clusters of academic enquiry to underscore their importance in terms of ensuring a consistent POE approach adopted and securing subjective feedback from building users. These conclusions have largely stemmed from studies conducted on higher education institutions vis-à-vis the wider built environment (c.f. Garbowski and Mathiassen 2013; García-Peñalvo and Conde 2013) - this is most likely because researchers have readily available access to buildings within their own host institution that support POE implementation. However, researchers have hitherto failed to influence built environment practitioners' adoption of POE in practice (c.f. Bordass and Leaman, 2005; Alborz and Berardi, 2015). In addition to a CoP body being developed, a plethora of potential financial and non-financial incentives are apparent and gravitate around building benchmarking. For example, environmental based legislative instruments could be used to set a minimum level of building performance to be expected to support existing rating schemes such as Leadership in Energy and Environmental Design (LEED) (cf. Ofori-Boadu et al., 2012; Martek et al., 2019). At present, such schemes are supported by government for government buildings but are not mandatory for non-government buildings (Ofori-Boadu et al., 2012). Alternatively, building performance could be used to set the level of financial revenue streams accrued from building users, i.e. higher performing buildings recover higher rental rates or purchase values. Incentives could also present an opportunity to remove overriding fears of practitioners regarding the value within POE implementation and how competitors could benefit from such (c.f. Preiser and Vischer, 2005; Olivia and Christopher, 2014).

Ultimately market forces are required to create demand for POEs and that may require further education and marketing to the general public (Martek et al., 2019) - perhaps under the guises of finance savings, environmental performance and user comfort. Whatever the solution to the POE uptake problem domain, it is apparent that a notable lack of a CoP within academia and practice has hitherto failed to embed POE as an integral part of a building's life cycle. Moreover, other initiatives (e.g. BIM, digitizing the built environment, industry 4.0 or environmental legislation) 
are conspicuous by their absence in literature reviewed - yet, POE arguably represents the best means of measuring the success of these initiatives within the built environment.

\section{Theory Development}

Using knowledge accrued from this research, Figure 7 was constructed depicting a theoretical $2 \mathrm{x}$ 2 matrix for digitalising the built environment which incorporates similarly aligned fields of built environment research. The x-axis represents the financial importance of a particular established field of study to a development's life cycle. The y-axis indicates the frequency of academic literature produced on particular areas of built environment research. Cleaning and maintenance $(f$ $=3,062$ with the first citation in 1978), whilst critical to the operation of a built asset, has largely been amalgamated into the larger Facilities Management (FM) field of research $(f=36,583$ with the first citation in 1976). BIM ( $f=51,937$ with the first citation in 1988) has a limited impact upon the operational phase of built assets' life cycles at present, although the emergent fields of 'BIM in FM' and 'Digital Asset Management' ( $f=613$ with the first citation in 1992 and $f=527$ research items with first citation in 2000 respectively) indicate significant research efforts to amend this. POE ( $f=515$ with the first citation in 1981) can be adjudged to have had a far greater impact upon the financial performance of a development's life cycle, yet has received substantially less academic attention. Future work is however required to empirically test this emergent theory.

\section{[Insert Figure 7 about here]}

Disruptive technologies such as BIM drive innovation and offer digital solutions for well documented and persistent issues within the built environment (c.f. Eastman et al., 2011; Motamedi et al., 2011; Race, 2013; Kensek, 2014a; Kensek, 2014b; Thomson and Boehm, 2015 Chan et al., 2016). However, whilst increasing the application of disruptive innovations generates voluminous data/information on buildings per se, such does not automatically translate into knowledge or wisdom. If practitioners were to utilise POE to evaluate user feedback and learn from the building's functionality and performance during its in-use phase, then the design feedback loop originally envisaged by Pärn et al. (2017) could readily be realised. At present, POE has largely utilised manual paper-based feedback mechanisms and has been perceived to create problems, including: i) inadequate funding to conduct a POE (Vischer, 2001; Zimmerman and Martin, 2001; Riley et al., 2010); ii) lack of clarity on who is responsible for the evaluation (Bordass and Leaman, 2005; Riley et al., 2010); and iii) the mitigation of liability of the project stakeholders regarding any issues highlighted by the POE (Zimmerman and Martin, 2001; Jauzens 
et al., 2003; Khosrowshahi and Arayici, 2012; Jiao et al., 2013). Consequently, the literature (augmented by anecdotal evidence from industry) suggests that POE is either not used or that the data generated is not exploited to its fully inherent capacity. There appears to be an ominous disconnect between building users and designers and perhaps a 'building handover' is symbolic of designer abdication of performance liability? Building upon these theoretical ideas, Figure 8 presents a triumvirate of BIM, FM and POE. The figure illustrates that the integration of BIM in FM has many palpable benefits that could be realised via a POE feedback mechanism (cf. Pärn et al., 2017). The application of this 'missing link' within the digital development process could contribute to accelerating the development of smart buildings and cities. Again, future work is required to test this theory and measure the impact that POE could have upon expediting smart buildings and cities development.

[Insert Figure 8 about here]

\section{Research Limitations}

Using an interpretivist epistemological lens as part of an inductive research approach has several significant limitations. First, interpretivist researchers assume that access to reality is only through social constructs such as the prevailing academic discourse on POE (Antwi and Hamza, 2015). Second, and as a branch of positivism, the interpretivist philosophical position also emphasises qualitative vis-a-vis quantitative analysis (Symon et al., 2016). The subjective nature of qualitative research can: introduce researcher bias into the study; be subject to literature searching practices that may omit significant research; and introduce translation errors (cf. Mallett et al., 2012). Third, the interpretivist approach cannot be generalised because the data and findings elucidated upon are heavily influenced by the researcher's personal views and values (Kiernan and Hill, 2018). These limitations apart, all research has a beginning and one significant benefit of an interpretivist approach is the generation of new theories that can signpost future research direction.

\section{CONCLUSIONS}

Whilst related research published has focused on specific aspects of conducting a POE (i.e. human comfort or energy consumption), this research presented represents the first detailed 'holistic examination' of extant literature of POE. Findings highlight that a significant dearth of relevant research is apparent and moreover, that a $\mathrm{CoP}$ in this field of study is needed to widen practitioner participation and their consistent implementation of POE. This finding is somewhat enigmatic given that POE is fundamental to measuring the technical and functional performance of current buildings and improving the designs of future buildings developed. Moreover, consistency of POE 
implementation is essential particularly when comparing between buildings. Without reliable data and information, this research posits that important knowledge and wisdom required to enable smart building and smart city developments will be significantly hampered. Specifically, architects, designers and contractors should work with facilities management teams post building occupation to undertake POEs (that measure building performance across all pertinent benchmarking criteria (energy consumption, lighting and heating control etc.)) to ensure that future designs perform as they were envisaged at conception. At present, prominent members of the design and construction team rarely contribute to the POE process and so the opportunity to learn from mistakes or develop improvements is largely lost. Such a recommendation may require changes in procurement processes to ensure that all project stakeholders involved throughout the building's whole life cycle are involved in POE.

A number of practitioner barriers to POE implementation were also observed and reported upon but prominent issues related to: scarce POE funding; unclear lines of responsibility for conducting POE; and liability mitigation for any issues highlighted by the POE. These barriers perhaps explain why the subject area fails to attract research funding and wider research activity - as evidenced by the small pool of fragmented research being conducted in the field. To overcome these barriers, future work is required to expand the current research study and engender wider practitioner and academic debate. Such work may include: i) reporting upon case studies of POE implementation within wider industry (vis-à-vis higher education institutions) to report upon examples of practice and provide tangible evidence of benefits to be accrued. Such work could be used as the basis for changing attitudes towards POE and educate future generations of practitioners; ii) working with professional bodies and higher education institutions to ensure that pertinent under- and postgraduate awards (or continual professional development programmes) give sufficient coverage on how to conduct a POE and the benefits that such yields for business and society. To change the prevailing culture within the AECO sector will require a cohesive effort to bridge the divide between academia and practice using factual evidence accrued from case studies; iii) developing a standardised approach to conducting a POE that would facilitate direct comparison between POEs conducted for various building developments - such work would enable the creation of a wider community of practice and knowledge bank that would feed into taught curricular and industry practice. Present variations between competing POE processes further exacerbate barriers reported upon and thus prevent wider POE implementation; and iv) empirically testing or refining the theories and interpretations emanating from this inductive research (for example, the theoretical matrix for digitalising the built environment). Deductive research is now required to 
1 either prove or disprove the work presented as a means of advancing research knowledge and 2 practitioner attitudes.

3 


\section{REFERENCES}

Acharya, R. H. and Sadath, A.C. (2019) Energy Poverty and Economic Development: Householdlevel Evidence from India, Energy and Buildings, Vol. 183, pp. 785-791. DOI: https://doi.org/10.1016/j.enbuild.2018.11.047

Adewunmi, Y., Omirin, M., Famuyiwa, F. and Farinloye, O. (2011) Post-occupancy Evaluation of Postgraduate Hostel Facilities, Facilities, Vol. 29, No. 3/4, pp. 149-168, DOI: 10.1108/02632771111109270.

Adeyeye, K., Piroozfar, P., Rosenkind, M., Winstanley, G. and Pegg, I. (2013) The Impact of Design Decisions on Post Occupancy Processes in School Buildings, Facilities, Vol. 31, No. 5/6, pp. 255-278, DOI: 10.1108/02632771311307142.

Ahuja, R. Sawhey, A. and Arif, M. (2016) Driving Lean and Green Project Outcomes Using BIM: A Qualitative Comparative Analysis, International Journal of Sustainable Built Environment, Vol. 6, No. 1, pp. 69-80, DOI: http://dx.doi.org/10.1016/j.ijsbe.2016.10.006

Alborz, N, and Berardi, U. (2015) A Post Occupancy Evaluation Framework for LEED Certified U.S Higher Education Residence Halls, Procedia Engineering, Vol. 118, pp. 19-27, DOI: 10.1016/j.proeng.2015.08.399.

Al horr, Y., Arif, M., Katafygiotou, M., Mazroei, A., Kaushik, A. and Elsarrag, E. (2016) Impact of Indoor Environmental Quality on Occupant Well-being and Comfort: A Review of the Literature, International Journal of Sustainable Built Environment, Vol 5, No. 1, pp. 1-11. DOI: https://doi.org/10.1016/j.ijsbe.2016.03.006

Antwi, S.K. and and Hamza, K. (2015) Qualitative and Quantitative Research Paradigms in Business Research: A Philosophical Reflection, European Journal of Business and Management, Vol. 7, No. 3, pp. 217-224. DOI:

Baird, G. (2010) Post-occupancy Evaluation and Probe: a New Zealand Perspective, Building Research and Information, Vol. 29, No. 6, pp. 469-472. DOI: https://doi.org/10.1080/09613210110072656

Bastian, M., Heymann, S. and Jacomy, M. (2009) Gephi: An Open Source Software for Exploiting and Manipulating Networks, International AAAI Conference on Weblogs and Social Media, Vol. 8, pp. 361-362, DOI: 10.13140/2.1.1341.1520.

Bing, L., Akintoye, A., Edwards, P.J. and Hardcastle, C. (2005) The Allocation of Risk in PPP/PFI Construction Projects in the UK, International Journal of Business Management, Vol. 23, No. 1, pp. 25-35, DOI: https://doi.org/10.1016/j.ijproman.2004.04.006 
Bordass, B. and Leaman, A. (2005) Making Feedback and Post-occupancy Evaluation Routine 1: A Portfolio of Feedback Techniques, Building Research and Information, Vol. 33, No. 4, pp. 347-352. DOI: https://doi.org/10.1080/09613210500162016

Bordass, B., Bunn, R., Cohen, R., Ruyssevelt, P., Standeven, M. and Leaman, A. (1999) The PROBE Project: Technical Lessons from PROBE 2, CIBSE National Conference.

Bosch, A., Volker, L. and Koutamanis, A. (2014) BIM in the Operations Stage: Bottlenecks and Implications for Owners, Built Environment Project and Asset Management, Vol. 5, No. 3, pp. 331-343, DOI: 10.1108/BEPAM-03-2014-0017.

Brown, C. (2015) The Power of Qualitative Data in Post-occupancy Evaluations of Residential High-rise Buildings, Journal of Housing and the Built Environment, Vol. 31, pp. 605620, DOI: 10.1007/s10901-015-9481-2.

BUS Methodology (2017) BUS Methodology. Available via: https://www.busmethodology.org.uk/about.html [Accessed: May 2018].

Chan, B., Guan, H., Jo, J., Blumenstein, M. and Wang, J. (2016) Defining a Conceptual Framework for Integration of Modelling and Advanced Imaging for Improving Reliability and Efficiency of Bridge Assessments, Journal of Civil Structural Health Monitoring, Vol. 6, pp. 703-714, DOI: 10.1007/s13349-016-0191-6.

Choi, J., Loftness, V. and Aziz, A. (2012) Post Occupancy Evaluation of 20 Office Buildings as Basis for Future IEQ Standards and Guidelines, Energy and Buildings, Vol. 46, pp. 167-175, DOI:10.1016/j.enbuild.2011.08.009.

CIC (2003) Construction Industry Council: Design Quality Indicator (2003) Available via: http://www.usablebuildings.co.uk/fp/OutputFiles/PdfFiles/FR7p1www.dqi.org.uk.p df [Accessed: May 2018].

Clarivate Analytics (2017) Web of Science Fact Book: It’s Time to get the Facts. Available via: https://cdn.clarivate.com/wp-content/uploads/2017/05/d6b7faae-3cc2-4186-8985a6ecc8cce1ee_Crv_WoS_Upsell_Factbook_A4_FA_LR_edits.pdf_[Accessed: April 2018]

Cobo, M. J., Lopez-Herrera, A. G., Herrera-Viedma, E. and Herrera, F. (2011) Science Mapping Software Tools, Review, Analysis, and Cooperative Study Among Tools, Journal of the Association for Information Science and Technology, Vol. 62, No. 7, pp. 13821402, DOI: 10.1002/asi.21525.

Cohen, R., Standeven, M., Bordass, B. and Leaman, A. (2001) Assessing Building Performance in Use 1: The PROBE Process, Building Research and Information, Vol. 29, No. 2, pp. 85-102, DOI: 10.1080/09613210010008018. 
1 Cooper, I. (2001) Post-occupancy Evaluation - Where Are You?, Building Research and Information, Vol. 29, No. 2, pp. 158-163, DOI: 10.1080/09613210010016820

Eastman, C., Teicholz, P., Sacks, R. and Liston, K. (2008) BIM Handbook: A Guide to Building Information Modelling for Owners, Managers, Designers, Engineers, and Contractors, 2nd ed., ISBN: 9780470541371 , Wiley, NJ.

El shenawy, A. and Zmeureanu, R. (2013) Energy-based Index for Assessing the Building Sustainability, Building and Environment, Vol. 60, pp. 202-210, DOI: 10.1016/j.buildenv.2012.10.019.

Gana, V., Giridharan, R. and Watkins, R. (2018) Application of Soft Landings in the Design Management Process of a Non-residential Building, Architectural Engineering and Design Management, Vol. 14, No. 3, pp. 178-193. DOI: 10.1080/17452007.2017.1324400

Garbowski, L. J. and Mathiassen, L. (2013) Real Estate Decision Making as Actor Networks, Journal of Corporate Research, Vol. 15, No. 2, pp. 136-149, DOI: 10.1108/JCRE-112012-0023.

García-Peñalvo, F. J. and Conde, M. Á. (2013) Using Informal Learning for Business Decision Making and Knowledge Management, Journal of Business Research, Vol. 67, pp. 686-691, DOI: http://dx.doi.org/10.1016/j.jbusres.2013.11.028

Gervásio, H., Santos, P., Martins, R. and Simöes da Silva, L. (2013) A Macro-component Approach for the Assessment of Building Sustainability in Early Stages of Design, Building and Environment, Vol. 73, pp. 256-270, DOI: http://dx.doi.org/10.1016/j.buildenv.2013.12.015

Göçer, Ö., Hua, Y. and Göçer, K. (2015) Completing the Missing Link in Building Design Process: Enhancing Post-occupancy Evaluation Method for Effective Feedback for Building Performance, Building and Environment, Vol. 89, pp. 14-27, DOI: http://dx.doi.org/10.1016/j.buildenv.2015.02.011

Gong, M., Simpson, A., Koh, L. and Tan, K. H. (2018) Inside Out: The Interrelationships of Sustainable Performance Metrics and its Effect on Business Decision Making: Theory and Practice, Resources, Conservation and Recycling, Vol. 128, pp. 155-166, DOI: http://dx.doi.org/10.1016/j.resconrec.2016.11.001

Guo, S.J. and Wei, T. (2016) Cost-effective Energy Measures Based on BIM Technology: Case Study at National Taiwan University, Energy and Buildings, Vol. 127, pp. 433-441, DOI: http://dx.doi.org/10.1016/j.enbuild.2016.06.015 
1 Hadjri, K. and Crozier, C. (2008) Post-occupancy Evaluation: Purpose, Benefits and Barriers, Facilities, Vol. 27, No. 1/2, pp. 21-33, DOI: 10.1108/02632770910923063.

Harden, A., Thomas, J. (2010) Mixed Methods and Systematic Reviews, in: Tashakkori, A., Teddlie, C. (Eds.), Sage Handbook of Mixed Methods in Social \& Behavioral Research, 2nd ed. Sage, Thousand Oaks, California.

Hassanain, M. A. and Iftikhar, A. (2015) Framework Model for Post-occupancy Evaluation of School Facilities, Structural Survey, Vol. 33, No. 4/5, pp. 322-336, DOI: 10.1108/SS06-2015-0029.

Hassanain, M. A., Mathar, H. and Aker, A. (2016) Post-occupancy Evaluation of a University Student Cafeteria, Architectural Engineering and Design Management, Vol. 12, No. 1, pp. 67-77, DOI: http://dx.doi.org/10.1080/17452007.2015.1092941

Hassanain, M. A. and Mudhei, A. (2006) Post-occupancy Evaluation of Academic and Research Library Facilities, Structural Survey, Vol. 24, No. 3, pp. 230-239, DOI: 10.1108/02630800610678878.

He, Q., Wang, G., Luo, L., Shi, Q., Xie, J. and Meng, X. (2017) Mapping the Managerial Areas of Building Information Modeling (BIM) Using Scientometric Analysis, International Journal of Project Management, Vol. 35, No. 4, pp. 670-685, DOI: 10.1016/j.jproman.2016.08.001.

HEFCE (2006) Guide to Post Occupancy Evaluation. Available via: http://www.smg.ac.uk/documents/POEBrochureFinal06.pdf [Accessed: November 2017]

Hayvaerts, M., Hannes, K. and Onghena, P. (2016) Using Mixed Methods Research Synthesis for Literature Reviews (Mixed Methods Research Series), SAGE Publications, Thousand Oaks, California.

Husin, H.N., Nawawi, A.H., Ismail, F. and Khalila, N. (2012) Preliminary Survey of Integrated Safety Elements into Post Occupancy Evaluation for Malaysia's Low Cost Housing, Procedia - Social and Behavioral Sciences, Vol. 36, pp. 583-590. DOI: https://doi.org/10.1016/j.sbspro.2012.03.064

Ilesanmi, A.O. (2011) Post-occupancy Evaluation and Residents' Satisfaction with Public Housing in Lagos, Nigeria, Journal of Building Appraisal, Vol. 6, No. 2, pp. 153-169, DOI: 10.1057/jba.2010.20.

Jauzens, D., Grigg, P., Cohen, R., Watson, M. and Picton, E. (2003) Building Performance Feedback: Getting Started, BRE Digest 478, Building Research Establishment, Watford. 
Jiao, Y., Wang, Y., Zhang, S., Li, Y., Yang, B. and Yuan, L. (2013) A Cloud Approach to Unified Lifecycle Data Management in Architecture, Engineering, Construction and Facilities Management: Integrating BIMs and SNS, Advanced Engineering Informatics, Vol. 27, No. 2, pp. 173-188, DOI: http://dx.doi.org/10.1016/j.aei.2012.11.006

Kensek, K.M. (2014a) Building Information Modeling, ISBN: 9781306661829, Routledge, New York, NY.

Kensek, K.M. (2014b) Integration of Environmental Sensors with BIM: Case Studies Using Arduino, Dynamo, and Revit API, Informes de la Construcción, Vol. 66, No. 536, pp. 1-9, DOI:10.3989/ic.13.151.

Kessem, M., Kelly, G., Dawood, N., Serginson, M. and Lockley, S. (2014) BIM in Facilities Management Applications: A Case Study of a Large University Complex, Built Environment Project and Asset Management, Vol. 5, No. 3, pp. 261-277, DOI: 10.1108/BEPAM-02-2014-0011.

Khosrowshahi, F. and Arayici, Y. (2012) Roadmap from Implementation of BIM in the UK Construction Industry, Engineering, Construction and Architectural Management, Vol. 19, No. 6, pp. 610-635, DOI: 10.1108/09699981211277531.

Kiernan, M.D. and Hill, M. (2018) Framework Analysis: A Whole Paradigm Approach, Qualitative Research Journal, Vol. 18, No. 3, pp. 248-261. DOI: https://doi.org/10.1108/QRJ-D-17-00008

Leaman, A. (2004) Outside the Comfort Zone: Buildings and Basic Human Needs, Human Givens Journal, Vol. 11, No. 2, pp. 34-5.

Leaman, A. and Bordass, W. (2005) Making Feedback and Post-occupancy Evaluation Routine 1: A Portfolio of Feedback Techniques, Building Research and Information, Vol. 33, No. 4, pp. 347-52, DOI: 10.1080/09613210500162016.

Lindkvist, C. (2015) Contextualizing Learning Approaches which Shape BIM for Maintenance, Built Environment Project and Asset Management, Vol. 5, No. 3, pp. 318-330, DOI: 10.1108/BEPAM-03-2014-0018.

Liu, R. and Issa, R.R.A. (2014) Design for Maintenance Accessibility Using BIM Tools, Facilities, Vol. 32 No. 3/4, pp. 153-159, DOI: 10.1108/F-09-2011-0078.

Liu, S., Meng, X. and Tam, C. (2015) Building Information Modelling based Building Design Optimization for Sustainability, Energy and Buildings, Vol. 105, pp. 130-153, DOI: http://dx.doi.org/10.1016/j.enbuild.2015.06.037

Mallett, R., Hagen-Zanker, J., Slater, R. and Duvendack, M. (2012) The Benefits and Challenges of Using Systematic Reviews in International Development Research, Journal of 
Development Effectiveness, Vol. 4, No. 3, pp 445-455. DOI: https://doi.org/10.1080/19439342.2012.711342

Martek, I., Hosseini M. Reza., Shrestha, A,. Edwards, D.J. and Durdyev, S. (2019) Barriers Inhibiting the Transition to Sustainability within the Australian Construction Industry: An Investigation of Technical and Social Interactions, Journal of Cleaner $\begin{array}{llll}\text { Production, } & \text { Vol. } & 221, & \text { pp. }\end{array}$ https://doi.org/10.1016/j.jclepro.2018.11.166

McGrath, P.T. and Horton, M. (2011) A Post-occupancy Evaluation (POE) Study of Student Accommodation in an MMC/modular Building, Structural Survey, Vol. 29, No. 3, pp. 244-252, DOI 10.1108/02630801111148211.

Miller, L., Dorsey, J. and Jacobs, K. (2012) The Importance of Ergonomics to Sustainability throughout a Building’s Life Cycle, Work (Reading, Mass.), Vol. 41, pp. 2129-2132, DOI: 10.3233/WOR-2012-0647-2129.

Milutienė, E., Staniškis, J. K., Kručius, Augulienè, V. and Ardickas, D. (2012) Increase in Building Sustainability by Using Renewable Materials and Energy, Clean Technologies and Environmental Policy, Vol. 14, pp. 1075-1084, DOI: 10.1007/s10098-012-0505-2.

Motamedi, A., Saini, R., Hammad, A. and Zhu, B. (2011) Role-based Access to Facilities Lifecycle Information on RFID Tags, Advanced Engineering Informatics, Vol. 25, pp. 559-568, DOI: 10.1016/j.aei.2011.03.004.

Motawa, I. and Carter, K. (2013) Sustainable BIM-based Evaluation of Buildings, Procedia Social and Behavioral Sciences, Vol. 74, pp. 419-428. DOI: 10.1016/j.sbspro.2013.03.015.

Mustafa, F.A. (2017) Performance Assessment of Buildings via Post-occupancy Evaluation: A Case Study of the Building of the Architecture and Software Engineering Departments in Salahaddin University-Erbil, Iraq, Frontiers of Architectural Research, Vol. 6, pp. 412-429, DOI: http://dx.doi.org/10.1016/j.foar.2017.06.004

Nical, A.K. and Wodynski, W. (2016) Enhancing Facility Management Through BIM 6D, Procedia Engineering, DOI: 10.1016/j.proeng.2016.11.623.

Ofori-Boadu, A., Owusu-Manu, D., Edwards, D.J. and Holt, G.D. (2012) Exploration of Management Practices for LEED Projects: Lessons from Successful Green Building Contractors, Structural Survey, Vol. 30 No. 2, pp. 145-162. DOI: https://doi.org/10.1108/02630801211228743

O’Neill, M. and Duvall, C. (2005) A Six Sigma Quality Approach to Workplace Evaluation, Journal of Facilities Management, Vol. 3, No. 3, pp. 240-253, DOI: 10.1108/14725960510808509. 
1 Olivia, G.S. and Christopher, T.A. (2014) In-use Monitoring of Buildings: An Overview and Classification of Evaluation Methods, Energy and Buildings, Vol. 86, pp. 176-189, DOI: http://dx.doi.org/10.1016/j.enbuild.2014.10.005

Oraee, M., Hosseini, M. R., Papadonikolaki, E., Palliyaguru, R. and Arashpour, M. (2017) Collaboration in BIM-based Construction Networks: A Bibliometric-qualitative Literature Review, International Journal of Project Management, Vol. 35, pp. 12881301, DOI: http://dx.doi.org/10.1016/j.ijproman.2017.07.001

Pärn, E. A., Edwards, D. J. and Sing, M.C.P. (2017) The Building Information Modelling Trajectory in Facilities Management: A Review. Automation in Construction, Vol. 75, pp. 45-55. DOI:10.1016/j.autcon.2016.12.003

Petticrew, M. and Roberts, H. (2008) Why Do We Need Systematic Reviews? Blackwell Publishing Ltd.

Preiser, W.F.E. (1995) Post-occupancy Evaluation: How to Make Buildings Work Better, $\begin{array}{llllll}\text { Facilities, } & \text { Vol. } & \text { 13, } & \text { No. } & \text { 11, }\end{array}$ https://doi.org/10.1108/02632779510097787

Preiser, W.F.E. (2002) Toward universal design evaluation, 17th Conference International Association for People-Environment Studies: Culture, Quality of Life and Globalization: Problems and Challenges for the New Millennium, Corunna, Spain.

Preiser, W. and Vischer, J. (2005) Assessing Building Performance, Oxford: Elsevier ButterworthHeinemann.

Rebaño-Edwards, S. (2007) Modelling Perceptions of Building Quality - A Neural Network Approach, Building and Environment, Vol. 42, No. 7, pp. 2762-77, DOI: 10.1016/j.buildenv.2006.07.018.

Race, S. (2013) BIM Demystified, 2nd ed., ISBN: 9781859465202, RIBA Publishing, London.

Riley, M., Kokkarinen, N. and Pitt, M. (2010) Assessing Post Occupancy Evaluation in Higher Education Facilities, Journal of Facilities Management, Vol. 8, No. 3, pp. 202-213, DOI 10.1108/14725961011058839.

Roberts, C.J., Pärn, E.A., Edwards, D.J. and Aigbavboa, C. (2018) Digitalising Asset Management: Concomitant Benefits and Persistent Challenges, International Journal of Building Pathology and Adaptation, Vol. 36, No. 2, pp. 2398-4708, DOI: 10.1108/IJBPA-09-2017-0036.

Royal Institute of British Architects (1965) Handbook of Architectural Practice and Management, RIBA Publications, London. 
Royal Institute of British Architects (2010) Higher Education Design Quality Forum: Better Communications $=$ Better Projects, RIBA Publications, London .

Royal Institute of British Architects (2016) Post Occupancy Evaluation and Building Performance Evaluation: Primer. Available via: https://www.architecture.com//media/gathercontent/post-occupancy-evaluation/additionaldocuments/ribapoebpeprimerpdf.pdf [Accessed: July 2018]

Royal Institute of British Architects (2017a) Building Knowledge: Pathways to Post Occupancy Evaluation, Reading: Value of Architects. ISBN: 9780704915718.

Royal Institute of British Architects (2017b) Post Occupancy Evaluations: How the Government Can Get Most Out of Capital Funding Programmes. Available via: https://www.architecture.com/-/media/gathercontent/post-occupancyevaluations/additional-documents/ribapoepolicypaperpdf.pdf [Accessed: July 2018]

Shohet, I.M., Lavy-Leibovich, S. and Bar-On, D. (2003) Integrated Maintenance Monitoring of Hospital Buildings, Construction Management and Economics, Vol. 21, pp. 219-228, DOI: 10.1080/0144619032000079734.

Shoubi, M. V., Shoubi, M. V., Bagchi, A. and Barough, A. S. (2014) Reducing the Operational Energy Demand in Buildings using Building Information Modelling Tools and Sustainable Approaches, Ain Shams Engineering Journal, Vol. 6, pp. 41-55, DOI: http://dx.doi.org/10.1016/j.asej.2014.09.006

Skills Funding Agency (2014) Post-occupancy Evaluation Guide. Available via: https://www.gov.uk/government/uploads/system/uploads/attachment_data/file/3611 47/POE_Guidance.pdf [Accessed: July 2018]

Suddaby, R., Bruton, G.D. and Si, S.X. (2015) Entrepreneurship Through a Qualitative Lens: Insights on the Construction and/or Discovery of Entrepreneurial Opportunity, Journal of Business Venturing, Vol. 30, No. 1, pp. 1-10. DOI: https://doi.org/10.1016/j.jbusvent.2014.09.003.

Symon, G., Cassell, C. and Johnson, P. (2016) Evaluative Practices in Qualitative Management Research: A Critical Review, International Journal of Management Reviews, Vol. 20, No. 1, pp. 134-154. DOI: https://doi.org/10.1111/ijmr.12120

Sustainable Cities (2009) Post-occupancy. Available via: http://usablebuildings.co.uk/ [Accessed: May 2018].

Thomson, C. and Boehm, J. (2015) Automatic Geometry Generation from Point Clouds for BIM, Remote Sensing, Vol. 7, pp. 11753-11775, DOI: 10.3390/rs7091175. 
1 Tookaloo, A. and Smith, R. (2015) Post Occupancy Evaluation in Higher Education, Proceedia Engineering, Vol. 118, pp. 515-521, DOI: 10.1016/j.proeng.2015.08.470.

Turpin-Brooks, S. and Viccars, G. (2006) The Development of Robust Methods of Post Occupancy Evaluation, Facilities, Vol. 24, No. 5/6, pp. 177-196, DOI: 10.1108/02632770610665775.

Waltman, L., van Eck, N.J. and Noyons, E.C.M. (2010) A Unified Approach to Mapping and Clustering of Bibliometric Networks, Journal of Informetrics, Vol. 4, No. 4, pp. 629635, DOI: https://doi.org/10.1016/j.joi.2010.07.002

Wong, J. K. W. and Zhou, J. (2016) Enhancing Environmental Sustainability over Building Life Cycles through Green BIM: A Review, Automation in Construction, Vol. 57, pp. 156165, DOI: 10.1016/j.autcon.2015.06.003.

van Eck, N.J. and Waltman, L. (2010) Software Survey: VOSviewer, A Computer Program for Bibliometric Mapping, Scientometrics, Vol. 84, pp. 523-538, DOI: 10.1007/s11192009-0146-3.

van Eck, N.J. and Waltman, L. (2014) Visualizing Bibliometric Networks. In: Ding, Y., Rousseau, R., Wolfram, D. (Eds.), Measuring Scholarly Impact: Methods and Practice. Springer International Publishing, Cham.

Vischer, J. (2001) Post-occupancy Evaluation: A Multifaceted Tool for Building Improvement, Learning from Our Buildings: A State-of-the-practice Summary of Post-occupancy Evaluation, National Academy Press, Washington, DC, pp. 23-34.

Wauters, B. (2005) The Added Value of Facilities Management: Benchmarking Work Processes, Facilities, Vol. 23, No. 3/4, pp. 142-151, DOI: 10.1108/02632770510578511.

World Commission on Environment and Development (1987) Our Common Future, ISBN: 019282080X, Oxford University Press, Oxford.

Zhang, Y. and Barrett, P. (2010) Findings from a Post-occupancy Evaluation in the UK Primary Schools Sector, Facilities, Vol. 28, No. 13/14, pp. 641-656, DOI 10.1108/02632771011083685.

Zeisel, J. (1981) Inquiry by Design, Brooks-Cole, Monterey, CA.

Zimmerman, A. and Martin, M. (2001) Post-occupancy Evaluation: Benefits and Barriers, Building Research and Information, Vol. 29, No. 2, pp. 168-74. DOI: 10.1080/09613210010016857. 
1 Table 1 - Factors Preventing POE Implementation

\section{Inhibitor of POE Description}

Ownership. $\quad$ Ownership of the POE process within a collaborative team of developers is often a stumbling block to its execution (Riley et al., 2010). Mitigation of liability is a significant driving factor for individual built environment professionals within the team (Khosrowshahi and Arayici, 2012; Jiao et al., 2013). This is further exacerbated by a culture of fear, blame and conflict which is synonymous with the building sector (Jauzens et al., 2003).

Cost, procurement and Riley et al. (2010) assert two prominent questions when considering the POE incentives. process: i) which party is responsible for commissioning and funding the evaluation? and ii) which party is professionally responsible for carrying it out? When examining this dilemma from a client perspective, the client often believes the 'testing' phase of the building life cycle has already been paid for (Riley et al., 2010). Consequently, the factors of cost, failure to agree on POE measures and disjointed incentives to implement POE, represent significant barriers (c.f. Zimmerman and Martin, 2001; Vischer, 2001).

Education and culture. Within the AECO sector, many designers, builders and project managers believe that they are in possession of in-depth knowledge of building performance, when often such knowledge extends only to the experience required to create and adjust buildings (Bordass and Leaman, 2005). Furthermore, there remains a notable absence of any obligation or payment to undertake a POE and POE implementation does not feature in contemporary architectural courses (Cooper, 2001). 
Table 2 - POE Strategies

\begin{tabular}{|c|c|}
\hline POE Strategy & Description \\
\hline PROBE & $\begin{array}{l}\text { PROBE is designed to utilise both quantitative and qualitative data regarding: energy } \\
\text { consumption; occupant surveys and interviews; observational walkthroughs; and technical } \\
\text { reviews (Riley et al., 2010) }\end{array}$ \\
\hline $\begin{array}{ll}\text { BUS } & \text { Occupant } \\
\text { Survey } & \end{array}$ & $\begin{array}{l}\text { The Building Use Studies (BUS) occupant survey utilises questionnaires to gather end-user } \\
\text { feedback on considerations such as: thermal comfort; ventilation; lighting and noise; personal } \\
\text { control; space; design; and image (BUS Methodology, 2017). The BUS occupant survey uses } \\
\text { key performance indicators to benchmark against other facilities held on the company's } \\
\text { databases (Riley et al., 2010). }\end{array}$ \\
\hline CIC DQI & $\begin{array}{l}\text { Construction Industry Council (CIC) Design Quality Indicators (DQI) utilises a questionnaire } \\
\text { specifically designed to capture feedback from any individual (from the project team to } \\
\text { neighbours) over the course of the building's life cycle (CIC, 2003). }\end{array}$ \\
\hline OLS & $\begin{array}{l}\text { Overall Liking Score (OLS) analyses three aspects of sustainability, namely: i) economic; ii) } \\
\text { social; and iii) environmental (c.f. WCED, 1987). The OLS is predicated on an end-user } \\
\text { questionnaire designed to capture opinions on successes and potential improvements (Riley } \\
\text { et al., 2010). }\end{array}$ \\
\hline $\begin{array}{l}\text { HEDQF POE } \\
\text { Forum } \\
\text { Methodology }\end{array}$ & $\begin{array}{l}\text { The Higher Education Design Quality Forum (HEDQF) Post-occupancy Evaluation Forum } \\
\text { Methodology utilises facilitated seminars organised approximately a year after the handover } \\
\text { of the facility (RIBA, 2010). Unlike the other strategies, this method can be executed as part } \\
\text { of the HEFCE Guidance to Post-occupancy Evaluation, as opposed to simply being a stand- } \\
\text { alone strategy (HEFCE, 2006; RIBA, 2010). }\end{array}$ \\
\hline Soft Landings & $\begin{array}{l}\text { Soft Landings considers the whole life cycle of the building, committing resources into } \\
\text { consideration of: i) briefing; ii) pre-handover; and iii) the long term operation of the facility } \\
\text { (Sustainable Cities, 2009). Soft Landings creates an environment and ethos suitable for the } \\
\text { undertaking of a POE (Riley et al., 2010). }\end{array}$ \\
\hline HEFCE Guidance & $\begin{array}{l}\text { The HEFCE Guide to POE is the preeminent document used in the higher education sector } \\
\text { (Riley et al., 2010). It was developed with the intention of increasing the preciseness of: } \\
\text { benchmarking; management; and operation of educational buildings. The HEFCE Guidance } \\
\text { advises collection of data at specific intervals after handover of a facility to maximise its } \\
\text { usefulness: i) practitioner team feedback data collected between } 3 \text { to } 6 \text { months after handover } \\
\text { before the project team move on to future projects; ii) end-user feedback data collected } 9 \text { to } \\
18 \text { months after handover when building users have settled in; and iii) technical data from an } \\
\text { asset Building Management System, for instance after the initial snagging period (c.f. } \\
\text { HEFCE, 2006). }\end{array}$ \\
\hline
\end{tabular}


1 Figure 1 - Bibliometric Citation Visualisation of Researchers Contributing to the POE BOK

2

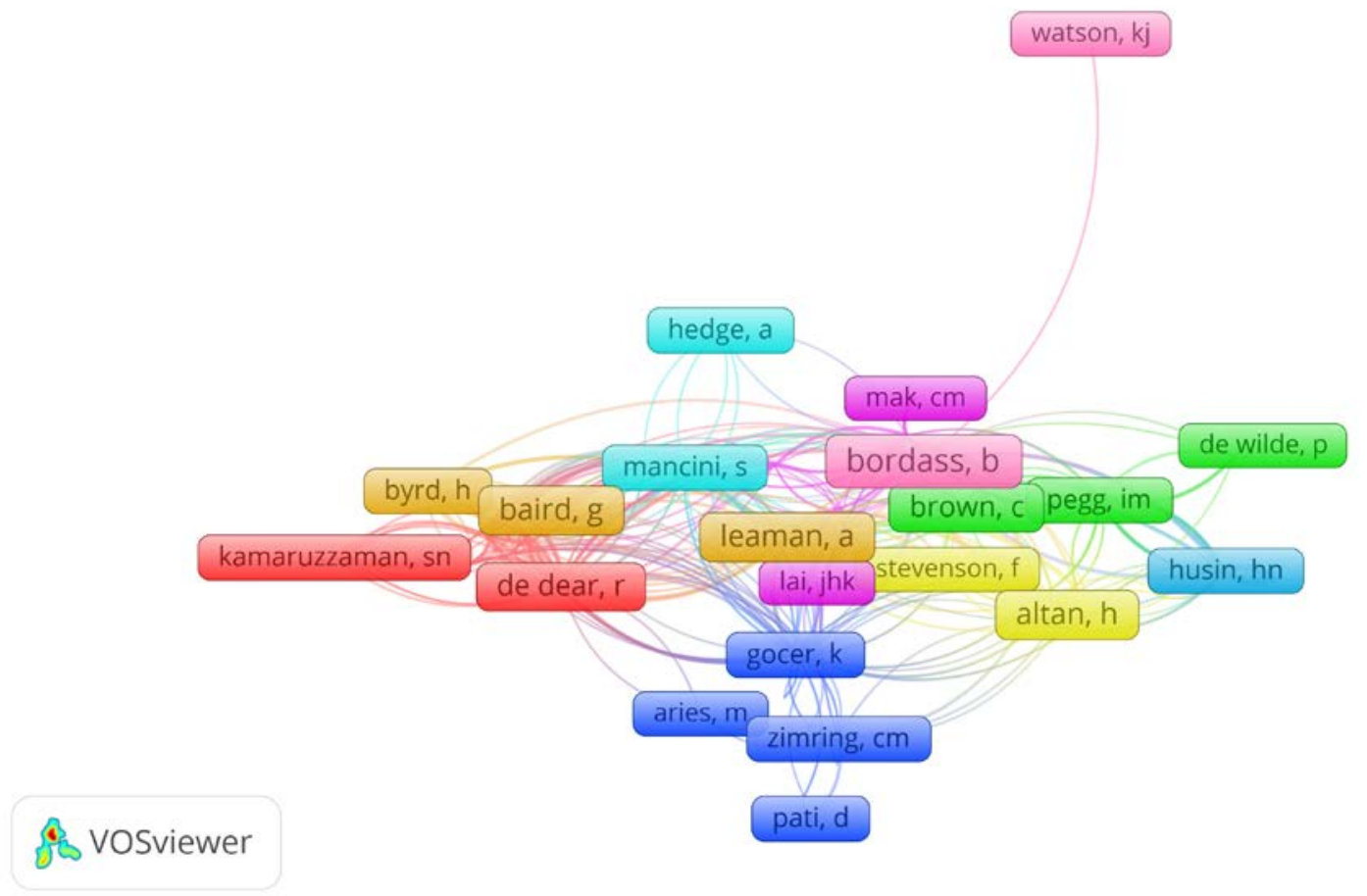

\begin{tabular}{|c|c|c|c|}
\hline \multicolumn{4}{|c|}{ Clusters: from left to right } \\
\hline Red & Watson, K.J & Loftness, V. & Green \\
\hline Salleh, N.M. & Cyan & Aziz, A. & Brown, C. \\
\hline Kamaruzzaman, S.N & Vietch, J.A. & Lai, J.H.K & Gorgolewski, M. \\
\hline Zawawi, E.M.A. & Mancini, S. & Sanni-Anibire, M.O & Wheeler, A. \\
\hline Zagreus, L. & Soebarto, V. & Hassanain, M.A. & Pegg, I.M. \\
\hline Arens, E. & Dorsey, J.A. & Hwang, T. & Allan, N. \\
\hline Zhang, $\mathrm{H}$. & Hedge, $\mathrm{A}$. & Kim, J.T. & Sodegar, B. \\
\hline Candido, C. & Birt, B.J. & Mak, C.M. & Goodhew, S. \\
\hline Schiavon, S. & Blue & Xue, $P$. & de Wilde, P. \\
\hline Thomas, L.E & Aries, M. & Yellow & Jones, R.V. \\
\hline Williams, M. & Shepley, M.M. & Stevenson, F. & Turquoise \\
\hline Kim, J. & Göçer, K. & Raslan, R. & Nawawi, A.H \\
\hline de Dear, $R$. & Preiser, W.F.E. & Altamirano-Medina, $\mathrm{H}$. & Ismail, F. \\
\hline Beige & Newton, C. & Guptar, R. & Husin, H.N. \\
\hline Lenoir, $\mathrm{A}$. & Pati, D. & Chandiwala, S. & Khalil, N. \\
\hline Garde, F. & Kantrowitz, M. & Nicol, F. & Labaki, L.C. \\
\hline Rasheed, E.O. & Hua, Y. & Altan, $\mathrm{H}$. & Kowaltowski, D.C.C.K. \\
\hline Byrd, H. & Zimring, C.M. & Patlakis, P. & Pina, S.A.M.G. \\
\hline Baird, G. & Yaldiz, E. & Santacruz, H.B. & Ruschel, R.C. \\
\hline Leaman, A. & Purple & Oreszczyn, T. & \\
\hline Bordass, B. & Choi, J.H. & Mumovic, D & \\
\hline
\end{tabular}


1 Figure 2 - Density Visualisation of Key Terms and Phrases within the POE BOK

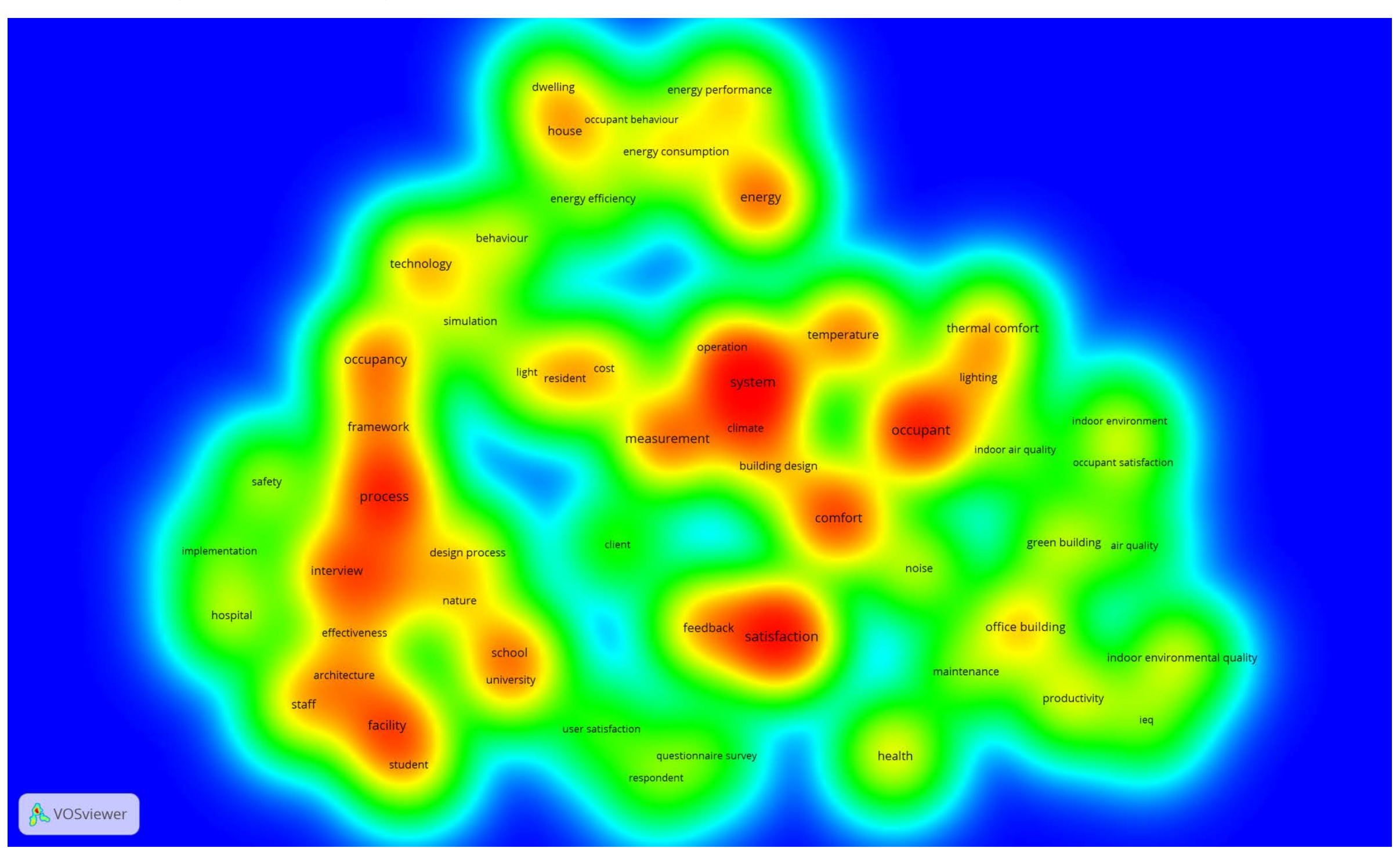


1 Figure 3 - Density Visualisation of the POE BOK with the Citation Date Overlay

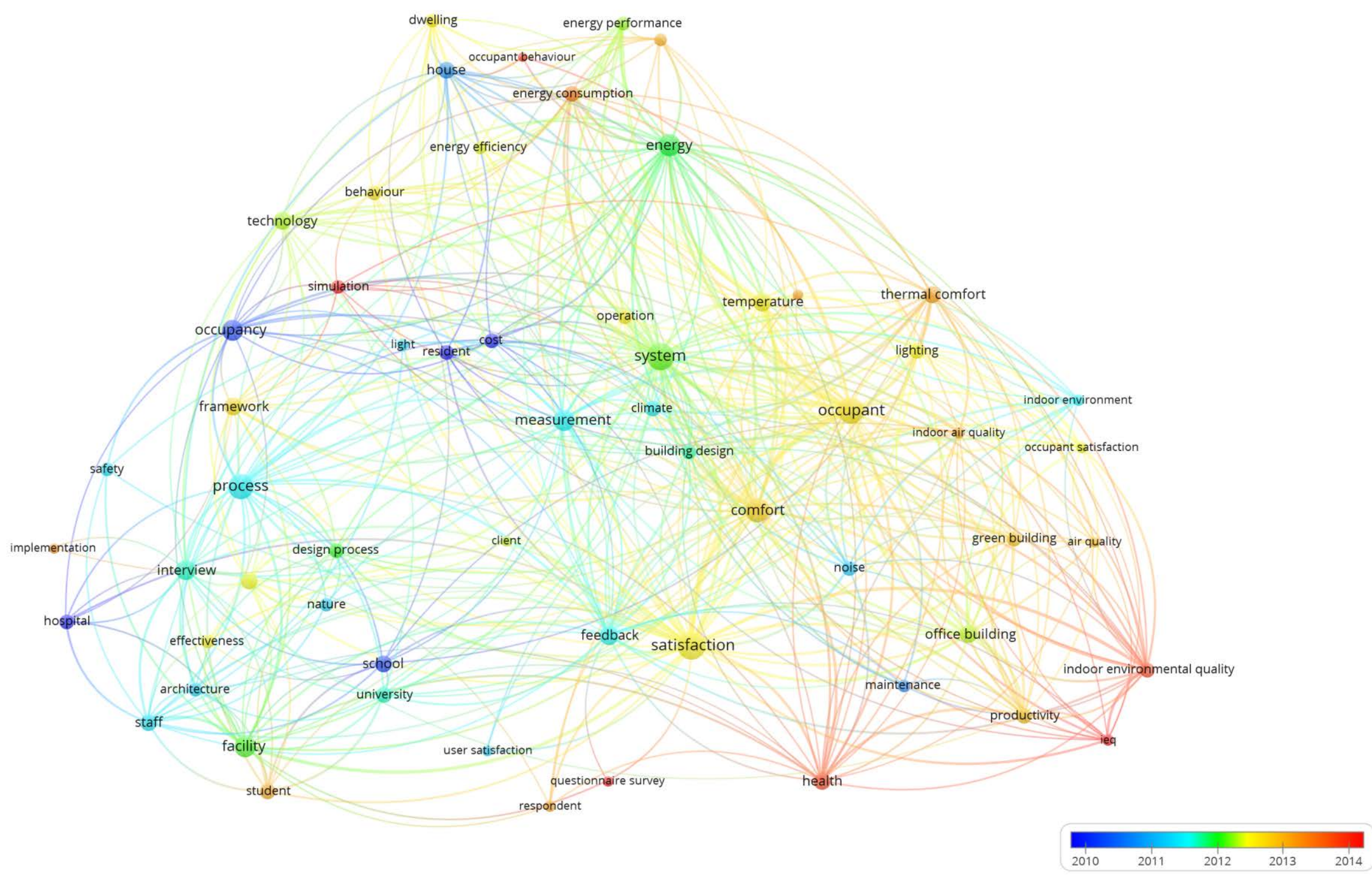


1 Figure 4 - Bibliographic Visualisation of Researchers Contributing to POE and Process Literature

2

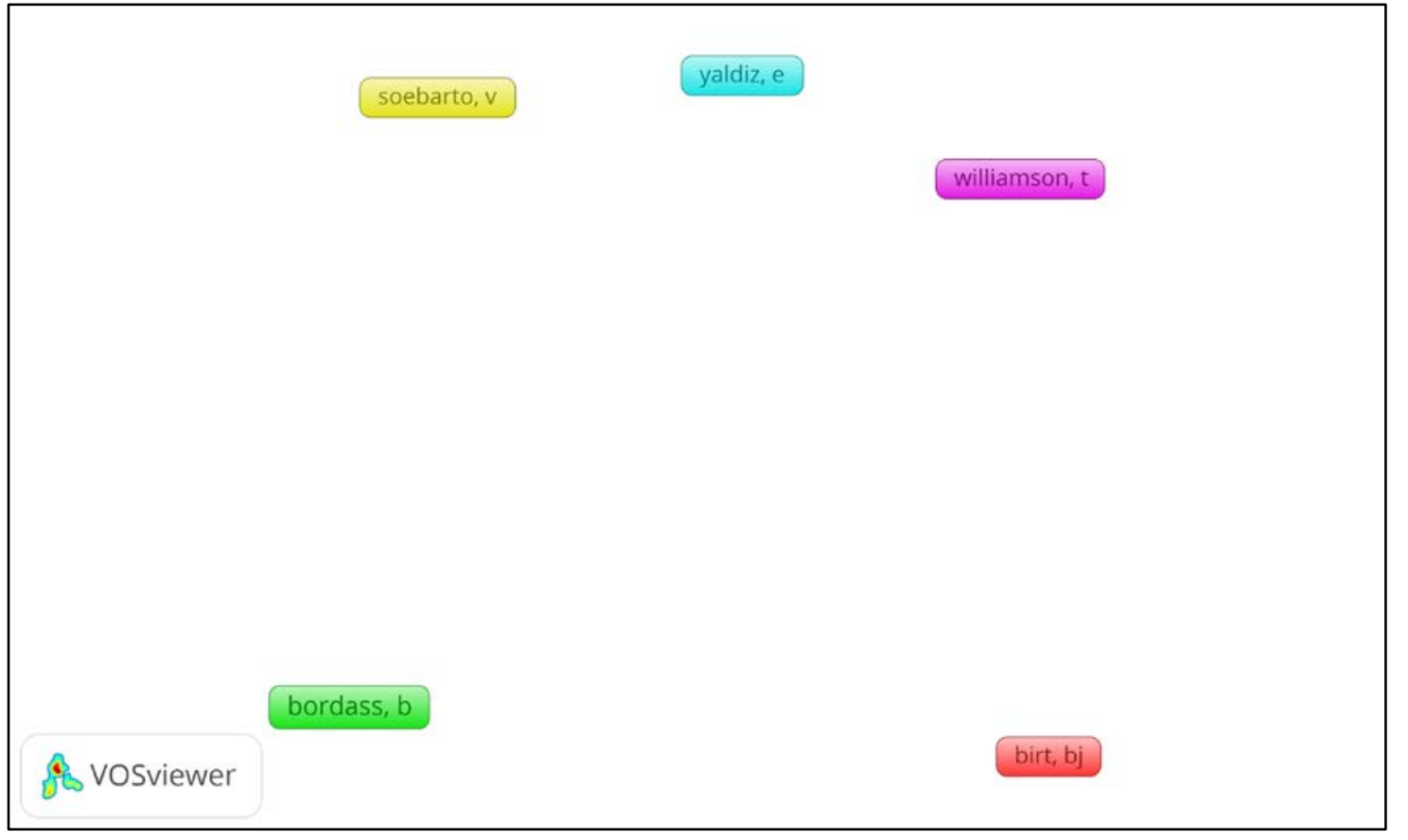

3

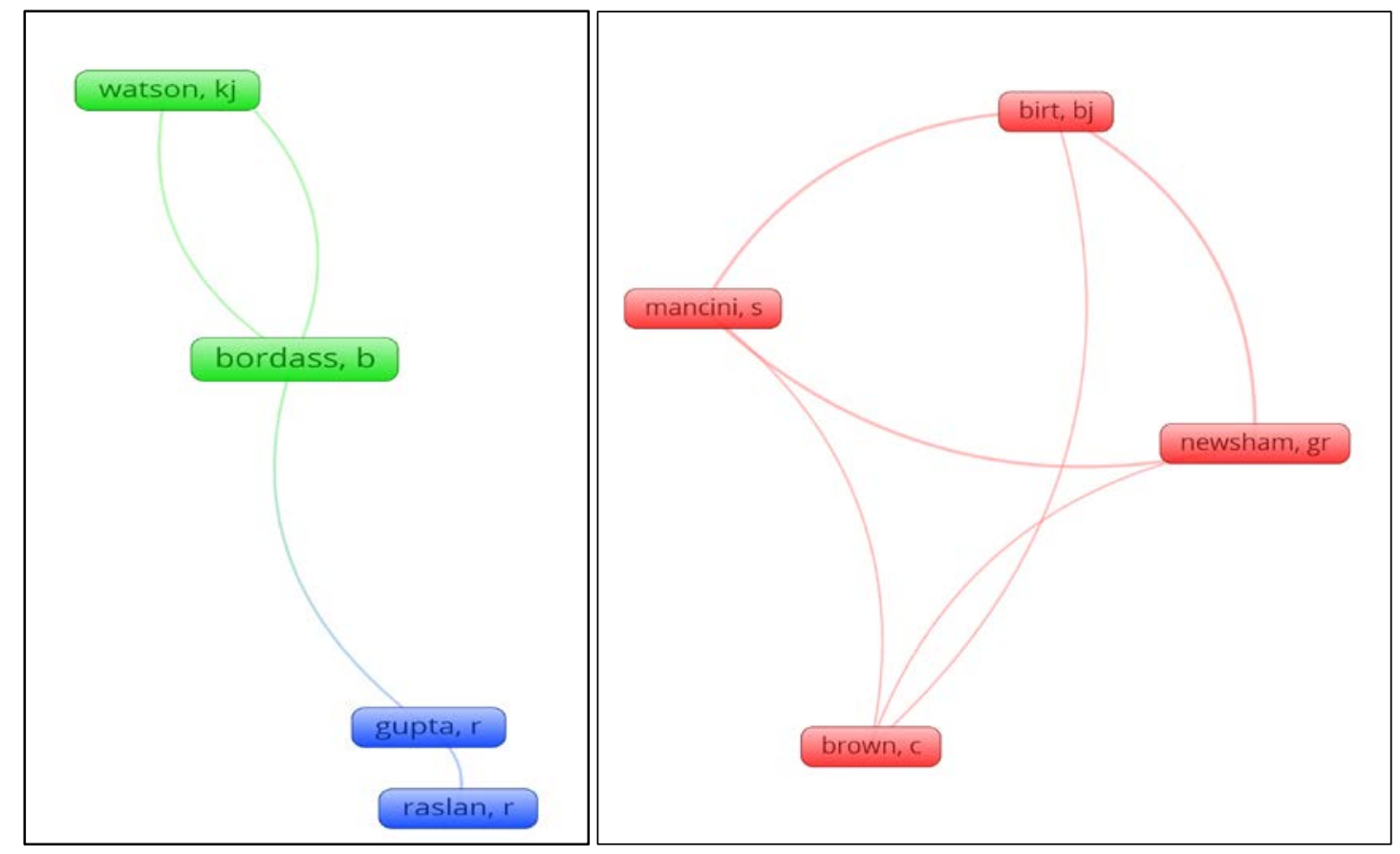

\begin{tabular}{|l|l|l|}
\hline $\begin{array}{l}\text { Authors (Co-authorship } \\
\text { overview) }\end{array}$ & Authors (Bordass Cluster) & Authors (Birt Cluster) \\
\hline Yellow & Green & Mancini, S. \\
Soebarto, V. & Watson, K.J. & Brown, C. \\
Cyan & Bordass, B. & Newsham, G.R. \\
Yaldiz, E. & Blue & Birt, B.J. \\
Purple & Gupter, R. & \\
Williamson, T. & Raslan, R. & \\
\hline
\end{tabular}


1 Figure 5 - Term Density Map of POE and Process Bibliometric Data

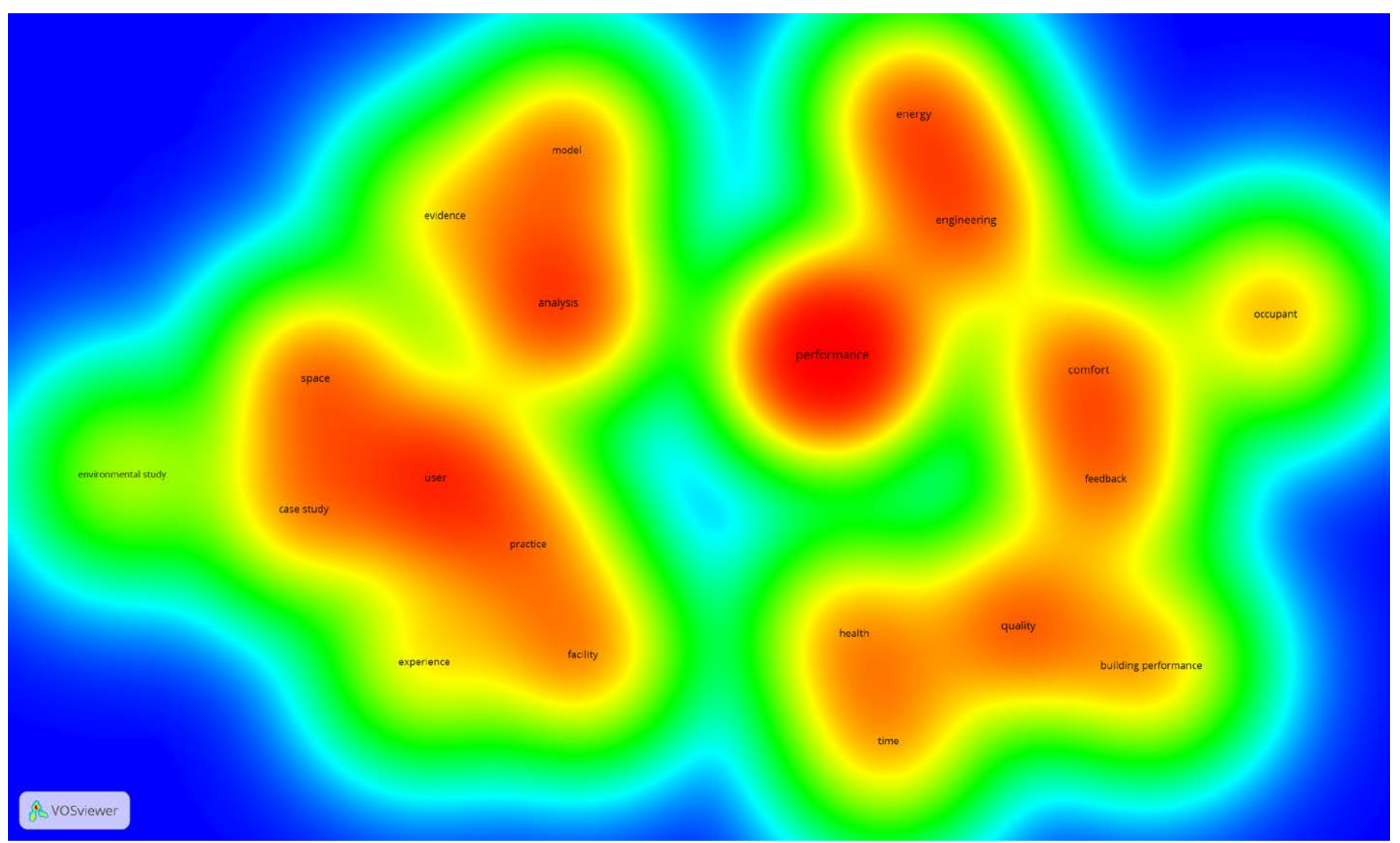


1 Figure 6 - Term Density Map for POE, Process and Benchmark

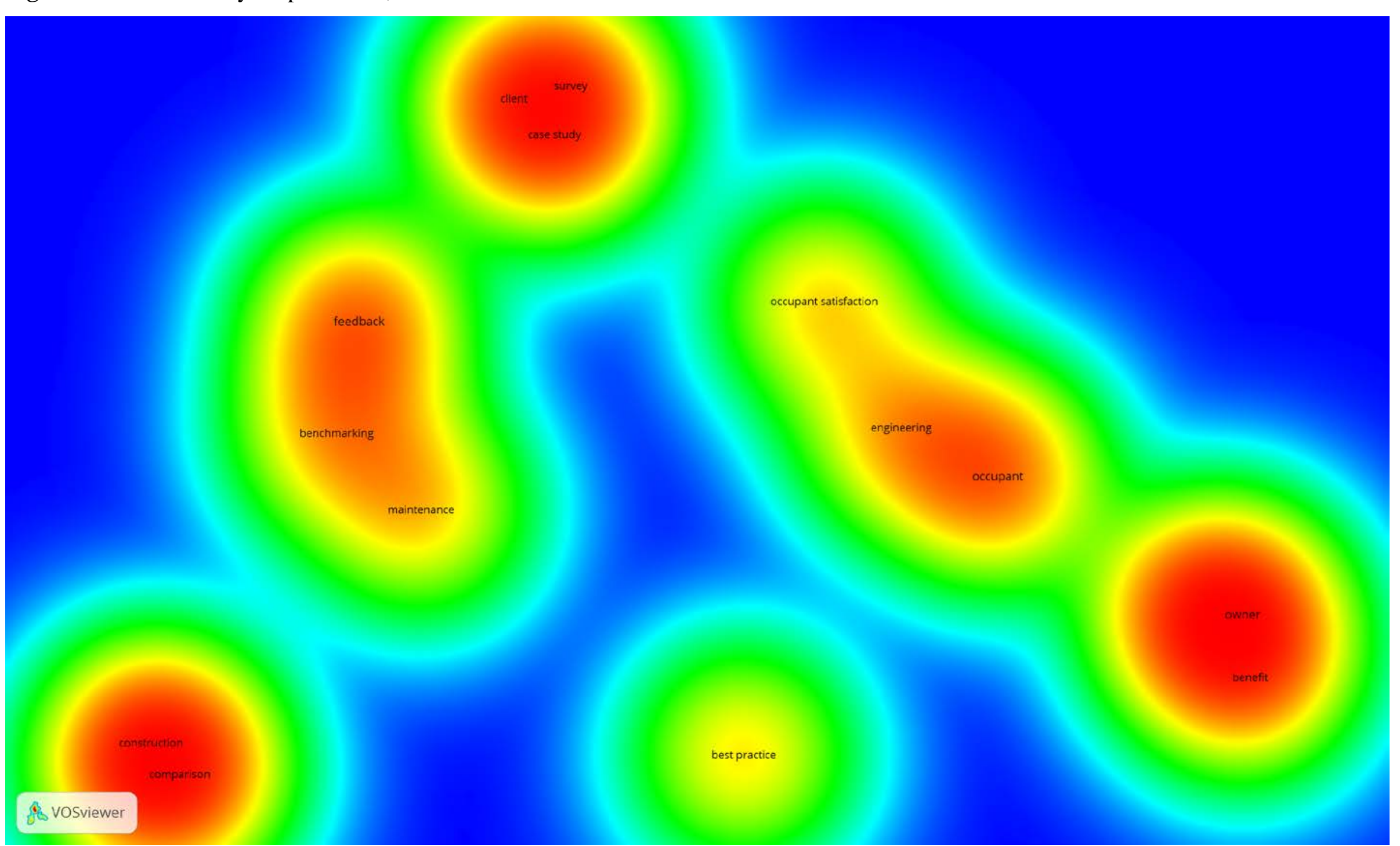




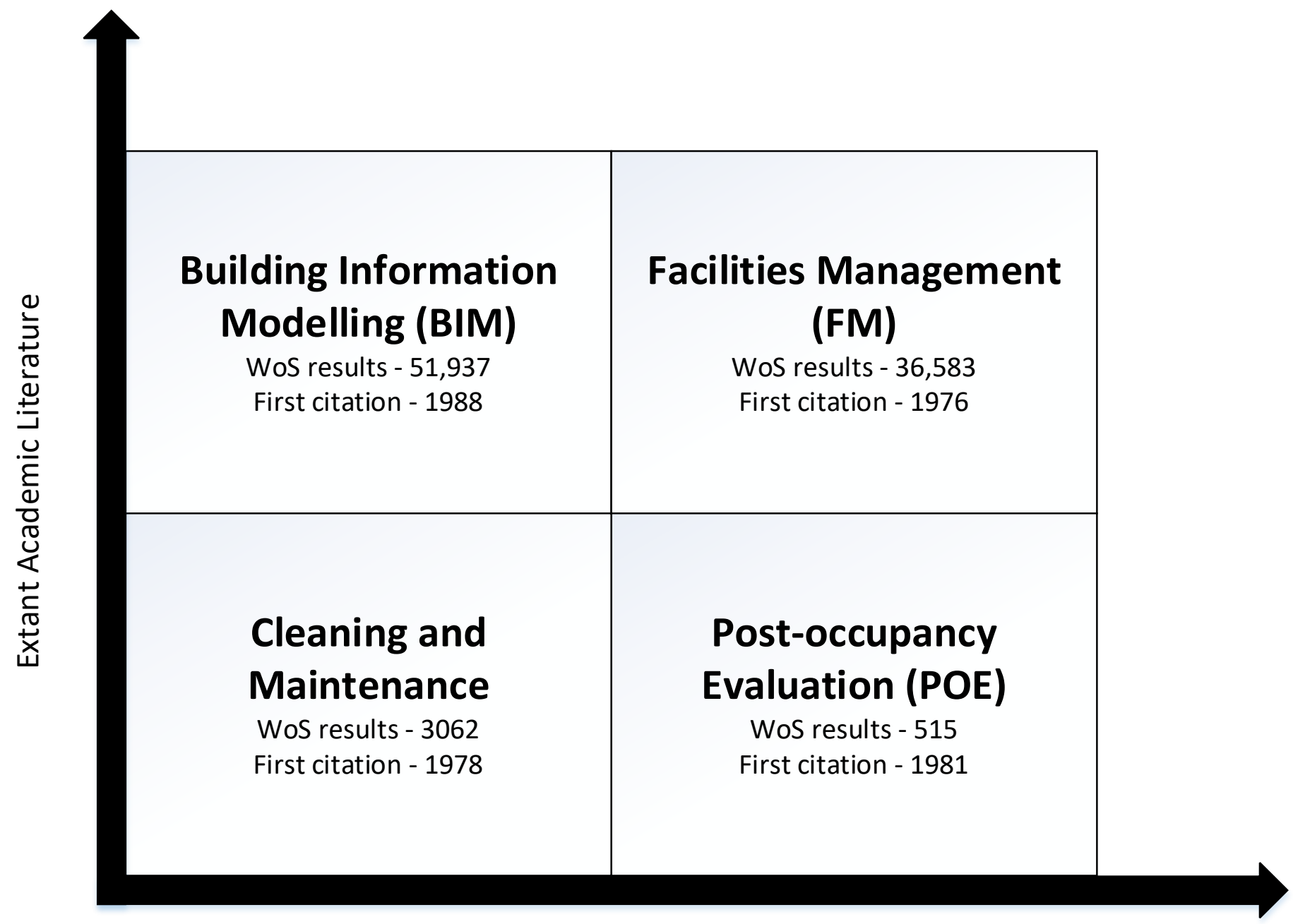

Financial Importance to Building Lifecycle 
1 Figure 8 - Future Trends in Smart Building/Smart City Development

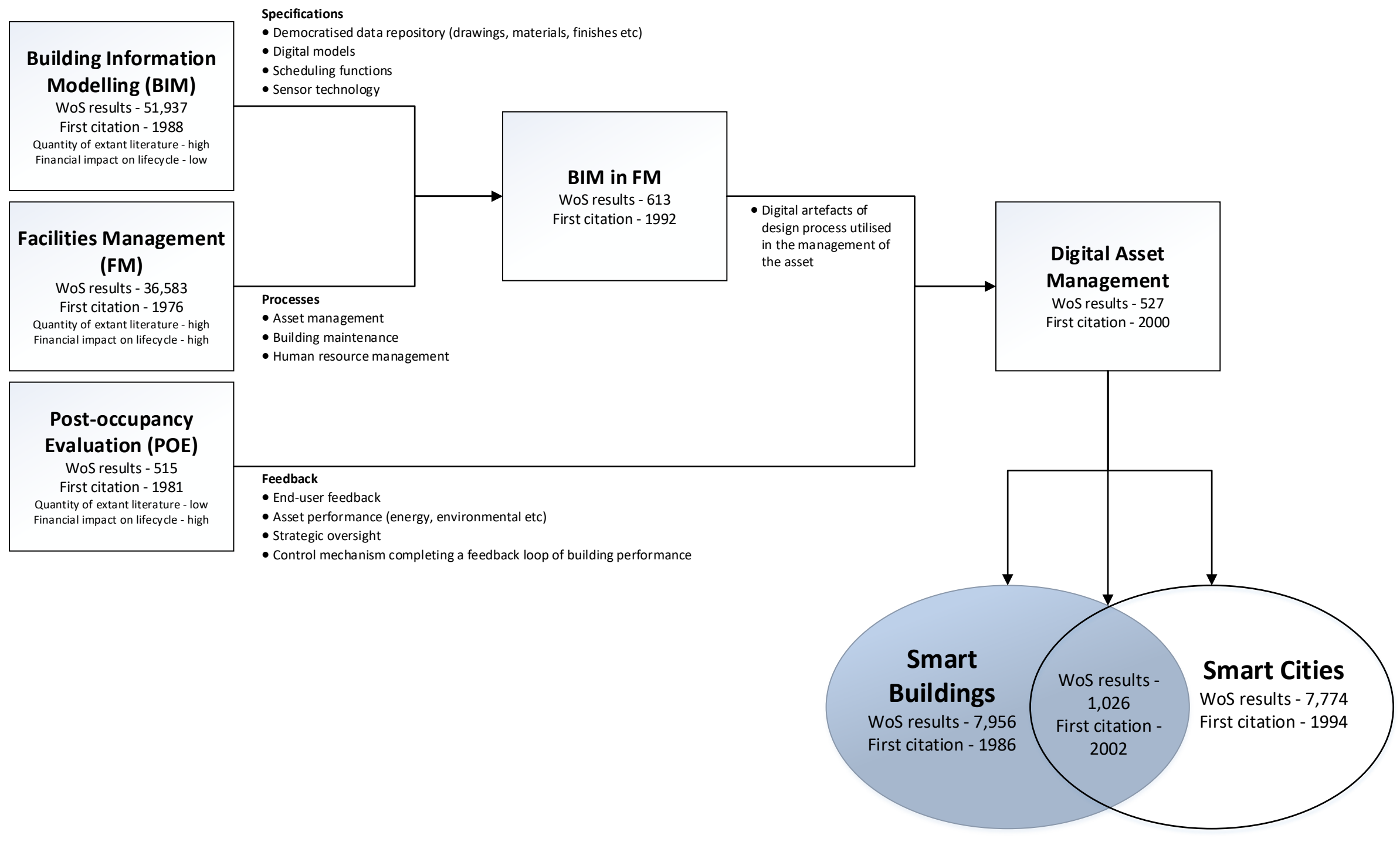

